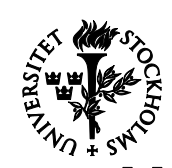

Stockholm

University

\title{
Fearful attention
}

Investigating event-related potentials in spider phobia

\section{Joakim Norberg}


(C)Joakim Norberg, Stockholm 2012

ISBN 978-91-7447-620-0

Printed in Sweden by Universitetsservice US-AB, Stockholm 2012

Distributor: Department of Psychology 
To my family 


\section{List of studies}

Study I: Norberg, J., \& Wiens, S. (submitted). Spiders leave no one untouched: Spider pictures increase emotional ERPs beyond arousal and valence.

Study II: Norberg, J., Peira, N., \& Wiens (2010). Never mind the spider: Late positive potentials to phobic threat at fixation are unaffected by perceptual load. Psychophysiology, 47, 1151-1158.

Study III: Norberg, J., \& Wiens, S. (submitted). Similar effects of manipulations of attention on processing of phobic and nonphobic pictures. 


\section{Contents}

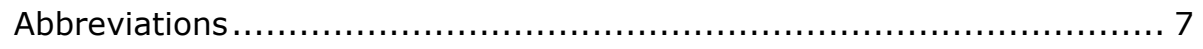

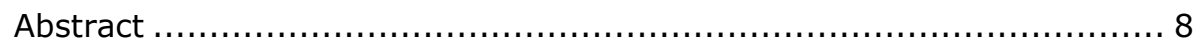

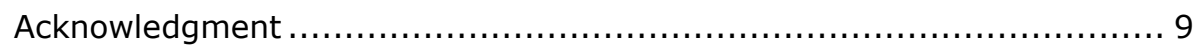

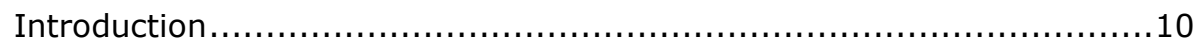

Selective attention .............................................................. 11

The concept of attention .................................................. 11

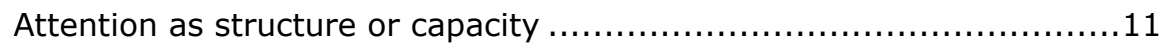

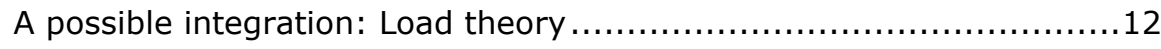

Visual attention ..............................................................

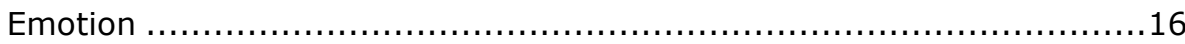

Types or dimensions of emotionality ..................................... 16

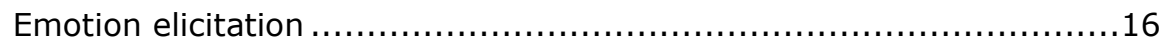

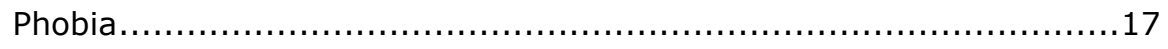

Emotion and attention......................................................... 19

Attentional bias to emotion ................................................ 19

Emotion without top-down attention ......................................20

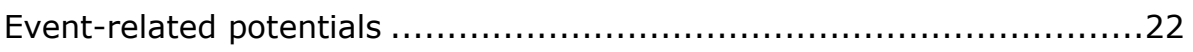

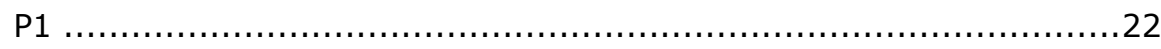

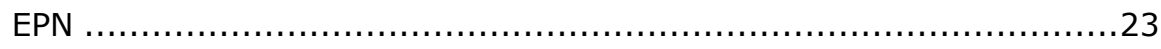

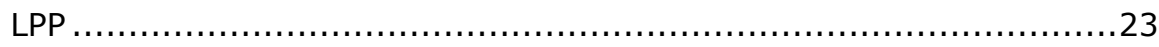

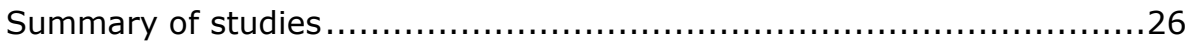

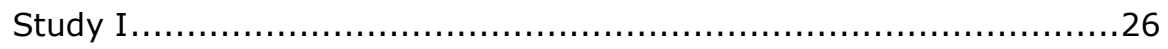


Study II

Study III 30

General discussion....... 33

References 


\section{Abbreviations}

ERP:

Event-Related Potential

EPN:

Early Posterior Negativity

LPP:

Late Positive Potential 


\section{Abstract}

Previous studies showed that emotional pictures capture attention. Further, this effect was decreased by manipulating spatial attention. In contrast, studies produced mixed findings for effects of perceptual load on attention to emotional pictures. Emotional pictures can be phobic or nonphobic. Because phobia might be an evolutionary adaption, it is possible that effects of phobic pictures on attention differ from effects of nonphobic emotional pictures. The present thesis aimed at investigating attention in spider phobia. Attention to emotional pictures was operationalized as event-related potentials (ERPs) (P1, early posterior negativity [EPN,] and late positive potential [LPP]). Two research questions were formulated. First, do phobic pictures evoke larger ERPs than what can be expected from arousal and valence? Second, are effects of spatial attention and perceptual load on ERPs the same for phobic and nonphobic emotional pictures? To investigate this, phobic and nonphobic negative pictures were presented to spider phobic and nonphobic participants. To determine effects of spatial attention on ERPs, participants were instructed to divert attention to a single letter that was presented in the periphery. To determine effects of perceptual load on ERPs, participants were instructed to perform a letter discrimination task on one, two, or three letters that were presented in the periphery. Study 1 showed enhanced LPP amplitudes to phobic pictures independent of arousal and valence. Further, this effect was present in both phobic and nonphobic participants. Study 2 showed that there was no effect of perceptual load on LPP to phobic pictures. Study 3 showed that spatial attention reduced LPP amplitudes, and to a similar extent for both phobic and nonphobic pictures. Further, perceptual load did not reduce EPN or LPP amplitudes to either phobic or nonphobic pictures. To conclude, the results suggest that phobic pictures evoke larger ERP amplitudes than nonphobic pictures. Still, ERPs to phobic and nonphobic pictures are moderated similarly by spatial attention and perceptual load. 


\section{Acknowledgments}

I first want to thank my supervisor Stefan Wiens for all his support during my work on this thesis. I am grateful to have had a supervisor with both great depth of knowledge and the generosity to share it. I also want to thank my co-supervisor, Jonas Persson, for being a strong support in case I needed you.

I then also want to thank my very first supervisor during my undergraduate years, Ove Almkvist, for introducing me to psychological science. And I want to thank Jan Carlsson, my second supervisor, for being a great friend and coworker in research.

I also want to thank all the present and former members of the cognitive neuroscience lab at the Department of Psychology: Henrik, Nathalie, Carin, Anders, and Elmeri. You have given me lots of valuable input and this thesis would not have been the same without you!

I also want to thank my other friends and colleagues at the Department of Psychology: Jonas, Veit, Jelena, Jesper, Martin, Artin, Constanze, Marianne, Fredrik, Kristina, Maria, Peter, Anna, Lena, Ninni, Cecilia, Jannica, Gustaf, Johan, Anne, Stina, and Roberto. I have had good times and interesting conversations with you all. Obviously, I also want to thank the Department of Psychology itself, for financing my four years of $\mathrm{PhD}$ studies, and taking such good care of me during this time.

I want to thank Per for important discussions.

My warmest thanks go to my family for all your support, both before, during, and after my time as a PhD student: mom and Lasse, dad and Susanne, mormor, Daniel and Anna. And Molly, of course, for just being cute.

Last, but not least, I would like to thank the participants in my studies. Without you, this thesis would never have been written! 


\section{Introduction}

Previous studies showed that emotional pictures capture attention. Further, this effect was decreased by manipulating spatial attention, that is, by averting attention away from the pictures. Attentional capture by emotional pictures can also be studied when participants perform a concurrent task that varies in attentional demands, that is, perceptual load. Studies produced mixed findings for effects of perceptual load on attention to emotional pictures. Emotional pictures can be phobic or nonphobic. Previous studies only studied nonphobic pictures. Because phobia might be an evolutionary adaption, it is possible that effects of phobic pictures on attention differ from effects of nonphobic emotional pictures.

The aim of the present thesis was to investigate attention in spider phobia. Two research questions were formulated:

- Do phobic pictures have larger effects on ERPs than what can be expected based on arousal and valence ratings?

- Are effects of spatial attention and perceptual load on ERPs the same for phobic and nonphobic emotional pictures? 


\section{Selective attention}

\section{The concept of attention}

Attention is a concept that originates from folk psychology, that is, every-day parlance, and as most other such concepts, its meaning is vague. To make things even more complicated, as psychologists have taken up the term and imported it into science, it has been given even more meanings that also tend to shift depending on the context of study. This makes it difficult to give a precise generic definition of "attention". However, in a very general sense it could be said that psychologists studying attention are interested in the limitations of human or animal information processing (Styles, 2006). The idea is that not all information that biological organisms are exposed to can be processed at the same time, at least not to the full extent. For that reason, some information needs to be selected at the expense of other information. Thus, attention is often associated with the epithet "selective", as in "selective attention".

Basically there are two questions of research on selective attention. The first concerns how people are able to chose some piece of information from a larger amount of information. In the auditory domain, this phenomenon is also known as "the cocktail party effect" (Cherry, 1953). When attending a cocktail party there are a lot of conversations going on at the same time. Still, people can somehow select a specific conversation and ignore the others. Psychologists are interested in what stimulus characteristics this selection is based on. The second question concerns what happens to the information that is unattended. The two questions of attentional research are complementary. When some information is selected, the rest of the information is unattended.

\section{Attention as structure or capacity}

Early research on attention was summarized by Broadbent (1958) and based on it he proposed a theory of information processing as a sequence consisting of two stages. He thought that at some point in the flow of information processing there is a bottleneck where only a lim- 
ited amount of information can pass. Thus, there must be a selection of what information to let by. Attention takes place after the bottleneck. The stage preceding the bottleneck is referred to as preattentive.

Attended processing was thought to suffer from processing limitations (Broadbent, 1958). In contrast, the preattentive stage would have no such limits. Another way to express this is to say that attended information is processed serially, i.e., one after the other in a temporal order, whereas preattentive information is processed in parallel, i.e., simultaneously.

Research following Broadbent's model was focused on determining the locus of the bottleneck. This research was framed in terms of early and late selection (Broadbent, 1958). Broadbent himself proposed that the bottleneck was situated early in the processing stream (1958). This means that stimuli are selected for attention based on their perceptual qualities, such as location, color or shape. From this follows that only the perceptual properties of unattended stimuli are processed. However, there were also findings indicating that semantic properties, such as the content of a spoken message, of unattended stimuli were processed (Moray, 1959). This led other researchers to suggest a late postperceptual selection in attention (e.g., Deutsch \& Deutsch, 1963).

An alternative to Broadbents's structural perspective on attention is the capacity perspective. According to this perspective, attention is a capacity or resource that exists in limited supply (e.g., Khaneman, 1973). The capacity perspective thus also stipulates that there are limitations to information processing, but does not attribute these limitations to structures. Instead, focus is shifted to the limited supply of attentional resources. Research on the capacity view has primarily been conducted in skill learning rather than the perceptual domain, with a special emphasis on multitasking (Styles, 2006). The idea is that during the performance of a task, attentional resources are consumed, thus causing decrements in the performance on other tasks. However, as a result of training, the need for attentional resources is decreased, making simultaneous performance of that task with other tasks possible without decrements in performance.

\section{A possible integration: Load Theory}

Load theory (Lavie, 1995) builds on the capacity perspective and defines attentional resources in perceptual terms. At the same time it 
suggests a solution to the debate between early and late selection originally initiated by Broadbent (1958). According to Load theory, attention is a limited perceptual resource. The extent to which a task is consuming this resource is referred to as its perceptual load. When perceptual load is low, attentional resources are still available and task irrelevant distractors will be processed. However, when perceptual load is high, attentional resources are depleted and processing of task irrelevant distractors will therefore be reduced or eliminated. So, the intention to ignore distractors is not enough to eliminate their processing. According to Load theory, loading of the perceptual system is also necessary. In this view, perception is seen as rather passive in that it processes stimuli until it is fully engaged.

Load theory has typically been explored with the response competition paradigm (Lavie, 1995), although effects of perceptual load have also been explored for implicit learning (Jiang \& Chun, 2001) and priming (Lavie \& Fox, 2000). In the response competition paradigm (Lavie, 1995), participants are instructed to respond to a target such as a letter while ignoring a distractor. The target is presented with other letters and perceptual load is manipulated by varying their number. For example, three letters are presented in low load and six letters are presented in high load. In addition to this, the distractor is presented on each trial. The distractor can be either compatible with the target (i.e., the same letter as the target) or incompatible (i.e., from the same pool of letters as the targets, but different from the type of letter as the target of the current trial) or neutral. During low perceptual load, longer reaction times are seen on incompatible trials than neutral trials. During high load, this effect is reduced or eliminated.

According to Load theory (Lavie, 1995), studies supporting early selection have typically used high perceptual load conditions and studies supporting late selection have typically used low perceptual load conditions. This is how the early/late selection debate is thought to be resolved. However, there are studies that show no moderation of distractor processing by perceptual load. More specifically, processing of task-irrelevant famous faces was found not to be moderated by perceptual load, indicating that stimuli of social significance might be except to constraints of perceptual load (Lavie, Ro \& Russell, 2003).

The concept of perceptual load is operationalized in terms of reaction times, but conceptually it involves more than just longer response la- 
tencies during high than low load. More specifically, perceptual load refers to the number of operations or units used in processing (Lavie, 1995). Neuroimaging studies showed reduced processing of distractors during high perceptual load already in the lateral geniculate nucleus of the thalamus (O'Connor, Fukui, Pinsk, \& Kastner, 2002) but also further up the processing stream from V1 (Schwartz, Vuilleumier, Hutton, Maravita, Dolan, \& Driver, 2005) up to V4 (Pinsk, Doniger \& Kastner, 2004; Schwartz et al., 2005) and V5 (Rees, Frith, \& Lavie, 1997).

It is important to separate perceptual load from general task difficulty. A task can be made more difficult, and thus increase reaction times, in many ways other than just increasing its perceptual load. For example, target size or contrast can be reduced. This data degradation also increases reaction times to targets but was shown to have the opposite effects to perceptual load, that is, distractor interference was higher during conditions of more rather than less data degradation (Lavie \& DeFockert, 2003).

Load theory also posits limited cognitive resources taxed by the so called cognitive load of the task (Lavie et al., 2010). These cognitive resources are thought to be needed to eliminate processing of distractors. In this way, cognitive load might be thought of in terms of executive functions or more specifically as response inhibition (e.g., Miyake et al., 2000; 2012). However, the tasks used to investigate effects of cognitive load on distractor processing have rather involved working memory and dual task coordination (Lavie et al., 2010). Importantly, just as data limitations, cognitive load is thought to have the opposite effects to perceptual load: high cognitive load involves greater distractor interference than low cognitive load. For example, when a task of selective attention was combined with a memory set of six digits (high cognitive load) rather than one (low cognitive load), distractor interference effects on reaction time increased (Lavie, Hist, de Fockert \& Viding, 2004). This was explained by high cognitive load draining cognitive resources that are needed to actively shut out distractors from processing.

\section{Visual attention}

Perceptual load tasks take place in the visuo-spatial modality. Several behavior studies showed spatial visual attention to be like a spotlight 
that moves across space (LaBerge, 1983). Some studies showed that this spotlight could be multiplied (Adamo, Pun, Pratt \& Ferber, 2008), meaning that it would be possible to attend to several places at the same time. However, these findings have not replicated well (Driver, \& Baylis, 1989; Jans, Peters, \& de Weerd, 2010). The idea of visual attention as a spotlight was also challenged by studies showing it to be more like a zoom lens with a diameter that can be extended to fit the task at hand (Eriksen \& st James, 1986). Other studies have also suggested visual attention to have even more bizarre shapes, e.g., like a doughnut (Muller \& Hubner, 2002). 


\section{Emotion}

\section{Types or dimensions of emotion}

The type approach to emotion suggests that emotion is best understood in terms of discrete categories (e.g., Darwin 1872; Ekman, 1992). These might be the emotional states that are known in folk psychology, such as "fear", "anger" or "shame". Empirical studies have failed to find definitive support for the type approach. For example, brain imaging (fMRI and PET) has failed to find consistent and specific activation for discrete emotions (Barrett \& Wager, 2006). The best support exists for the amygdala in fear, but even for this brain region, specificity is low as it shows activation also to positive stimuli and novelty (Barrett, 2006).

In contrast, the dimensional approach to emotion suggests that emotion is best understood in terms of a limited number of underlying constructs. Arousal (i.e., excitement) and valence (positive or negative) have been suggested as the dimensions of emotion (Lang \& Davis 2006). These are supposed to overlap with the biological motivational system of approach and avoidance (Konorski, 1967): Valence reflects which one of these systems is activated, with positive valence corresponding to the approach system, and negative valence corresponding to the avoidance system; Arousal corresponds to the degree of activation.

\section{Emotion elicitation}

An abundance of studies show that emotion can be successfully induced by pictures (Lang, Davis \& Öhman, 2000). To aid comparisons across studies, the International Affective Picture System (IAPS) was developed (Lang, Bradley \& Cuthbert, 2008). This includes negative (low valence), positive (high valence) and neutral (medium valence) pictures. Arousal and valence ratings of IAPS picture are related to each other, such that low (i.e., negative) and high (i.e., positive) valence ratings are both associated with high arousal ratings, whereas valence ratings in the medium range are associated with low arousal 
ratings. Negative pictures include pictures of threat and mutilated bodies, positive pictures include pictures of sex and sport, and neutral pictures include pictures of household objects and neutral faces.

Emotional picture viewing elicits enhanced activity in amygdala (Breiter et al., 1996; LaBar et al., 2001) and visual areas (Bradley et al., 2003; Fredrikson et al., 1993; Fredrikson, Wik, Annas, Ericson, \& Stone-Elander, 1995; Junghöfer, Sabatinelli, Bradley, Schupp, Elbert, Lang, 2006; Reiman et al., 1997), with a possible functional connectivity between these regions (e.g., Sabatinelli, Bradley, Fitzsimmons, Lang, 2005) in which the amygdala influences sensory cortex with top-down signals (Vuilleumier, 2005).

\section{Phobia}

Phobia is the most common anxiety disorder, with a lifetime prevalence ranging from 10\% to $18 \%$ (Bijl, 1998; Kessler, 2005; Moffitt, 2010). The most common phobia is fear of spiders, with a prevalence of $1.2 \%$ for men and $5.6 \%$ for women (Fredrikson, 1996). Phobia is usually thought to be the result of aversive conditioning (Field, 2006), that is Pavlovian or classical conditioning where a biologically innate fear response is coupled with a stimulus that does not by itself elicit it. In support, brain imaging show similar activation patterns for phobia and experimentally induced aversive conditioning in humans (Etkin \& Wager, 2007).

One problem for the explanation of phobia in terms of aversive conditioning is that people with phobia do not report traumatic events involving their phobic stimulus to a greater extent than people without phobia (Field, 2006). However, studies suggest that amnesia is greater in explicit memory systems than for procedural memory such as aversive conditioning (LeDoux, 1998). In fact, stress hormones that are induced during traumatic events might have opposite effects on episodic memory than conditioning: Whereas stress hormones cause deterioration of episodic memories, they might strengthen the formation of conditioned responses (LeDoux, 1998).

Another problem for the explanation of phobias in terms of aversive conditioning is that not all stimuli are equally probable to pose as phobic stimuli (Field, 2006). As noted, spiders are the most common phobic stimuli. In contrast, guns that are much more dangerous than spiders in the modern world are not at all common as phobic stimuli. 
Prepardness theory tries to account for this by suggesting that people are more easily conditioned to stimuli that posed as threats during human evolution (Seligman, 1971). 


\section{Emotion and attention}

There are two ways in which attention has implications for processing of emotional stimuli. Both effects capture different meanings of processing being "automatic". First, several studies, as summarized below, have shown that there are effects of emotional stimuli on attention, that is, there is an attentional bias to emotional stimuli. Second, there might also be effects of emotion that are independent of topdown attention. However, this latter proposition is still controversial.

\section{Attentional bias to emotion}

An abundance of studies suggest that attention is biased towards emotional stimuli. This has been shown in emotional versions of several paradigms used to study nonemotional attentional bias. For example, in the visual search task (Treisman, 1982) participants are instructed to find a target among distractors. The time taken to find conjunction targets increases linearly as a function of the number of distractors. However, emotion facilitates visual search in that emotional targets pop-out, that is, they are found immediately or at least much faster than nonemotional tagets. In contrast, emotion distracts in that finding nonemotional targets take longer time when the distractors are emotional rather than nonemotional

Further, in the emotional dot-probe task (Cooper \& Langton, 2006), a picture is shown at either the right or the left side on a computer screen. Shortly after, a dot appears on either side. If an emotional picture was shown before the dot appeared at the same place, participants detect the dot faster than if the picture was nonemotional. Conversely, if the emotional picture appeared in the wrong position, reaction time to the dot is slower.

Finally, in the Stroop task (Jensen \& Rohwer, 1966), participants are asked to name the color of monochromatic words of colors. Responses are slower when words are incompatible with the color that the words are printed in compared to when they are compatible. This effect is 
also achieved with emotional words (Paelecke, Paelecke-Habermann \& Borkenau, 2012). In the emotional Stroop, monochromatic emotional words are presented to participants that are asked to name the color. Responses are slower to emotional than nonemotional words, indicating that emotion interferes with the response.

These results can be accounted for by postulating two attentional systems, referred to as top-down or endogenous attention, and bottom-up or exogenous attention respectively (Muller, \& Rabbitt, 1989). Topdown attention is intentional, that is, it involves choosing what to attend to. In addition to this, some stimuli also attract attention by their own means, that is, they exert an "attentional capture". This is bottomup attention, and it is by definition involuntary. This is the first sense, i.e., by being involuntary, that processing is automatic.

\section{Emotion without top-down attention}

Emotional information is not only thought to have privileged access to attention. Emotional information might also be processed without attention. In this way, emotional stimuli will elicit emotional reactions also when attention is directed to or consumed by other tasks. Much research in this area has been conducted with brain imaging and focused on the amygdala which is thought to be at the center of emotional activation. For example, by using fMRI, Vuilleumier, Armony, Driver \& Dolan (2001) presented pictures of fearful and neutral faces in either attended or unattended locations. Results showed that location did not moderate emotional processing as indexed by amygdala activation, that is, emotional stimuli were processed to a similar extent in both attended and unattended locations.

However, numerous studies lack such effects. For example, Pessoa, Padmala \& Morland, (2005) also used fMRI and presented pictures of fearful and neutral faces at fixation to participants who were asked to perform a discrimination task on two bars flanking each side of the pictures. When the bar task was easy, there was amygdala activation to emotional pictures. However, when the bar task was made more demanding, amygdala activity was reduced. This result was thought to indicate that emotional stimuli are not processed when unattended.

Processing without attention, if possible, can be said to be automatic in a second sense of the term, that is, by not requiring attentional resources. Such processing can be differently accounted for by the struc- 
tural and capacity perspectives on attention. In the structural perspective, processing without attention is the same as preattentive processing. This processing is thought to have no limits on how much information that can be processed at any given time (Broadbent, 1958). In the capacity perspective, processing without attention is that which does not tax attentional resources (Styles, 2006).

The common story for how emotional processing without attention is possible departs from the idea that emotional information is processed along two separate roads that both end up in the amygdala (Ledoux, 1998). First, emotional information access the amygdala through visual cortex. This is referred to as the high road In addition to this, there is supposed to be a so called low road that is used by emotional information to access the amygdala directly from the thalamus, thereby bypassing the cortex. The low road corresponds to processing without attention. Because the low road is shorter than the high road, emotional information can be processed faster than nonemotional information by using this route.

In support for the existence of the low road, lesion studies on rodents found connections from the auditory thalamus to the amygdala (Ledoux, 1998). However, there is limited evidence for a low road in the visual system of humans and other primates (Pessoa \& Adolphs, 2010). Further, a model of cortical processing in primates that allows for multiple paths and shortcuts can fully account for the speed of emotional processing (Pessoa \& Adolphs, 2010). 


\section{Event-related potentials}

Because of their excellent temporal resolution, event related potentials (ERPs) are well suited to study attention (Luck, 2005). ERPs are brain potentials to specific events such as pictures, hidden in the spontaneous activity of the electroencephalogram (EEG). ERPs are usually given names depending on their positive or negative deflection and time of onset. By studying ERPs, it is possible to follow processing as it unfolds over time with high temporal resolution. However, the contribution of subcortical structures to ERPs are thought to be small because signals are weak and are probably degraded before reaching the scalp. For that reason, ERPs primarily reflect cortical activity. Still, the ERP technique has been used extensively in emotion research $(\mathrm{Ol}-$ ofsson, Nordin, Sequeira \& Polish, 2008). The present thesis focused on three EPRs: P1, the early posterior negativity (EPN), and the late positive potential (LPP).

\section{P1}

The P1 wave is seen over lateral occipital electrodes about $60-130$ ms poststimulus (Luck, 2005). The neural source of P1 was located with different algorithms on ERP data to extrastriate cortex (Clark, Fan \& Hillyard, 1995; Di Russo, Martinez, Sereno, Pitzalis \& Hillyard, 2002; Di Russo, Martinez \& Hillyard, 2003; Pourtois, Grandjean, Sander, \& Vuilleumier, 2004).

Given its neural origin, it would come as no surprise that P1 is sensitive to stimuli characteristics, such as contrast (Luck, 2005). Failure to control for such characteristics might explain the great variability seen in outcomes for studies on P1 with affective stimuli (Olofsson et al., 2008). Still, studies showed that P1 is sensitive to both arousal (Vogel $\&$ Luck, 2000) and valence in the form of a negativity bias (Olofsson et al., 2008).

The P1 was shown to be sensitive to selective attention in the dotprobe paradigm. Enhanced P1 amplitudes were found to probes pre- 
ceded by valid but not invalid cues (Clark \& Hillyard, 1996). These results was also obtained with emotional cues (Pourtois et al., 2004; Stormark, Nordby, Hugdahl \& , 1995). The results suggest that P1 might index attentional capture (Pourtois et al., 2004).

\section{EPN}

The early posterior negativity (EPN) is seen over temporal-occipital electrodes when neutral pictures are subtracted from emotional pictures (Weinberg \& Hajcak, 2010). Its starts about 120-150 ms after stimulus onset and can last up to $300 \mathrm{~ms}$ poststimulus (Peyk, Schupp, Keil, Elbert \& Junghofer, 2009).

EPN amplitudes are correlated with arousal (Leite, Carvalho, GaldoAlvarez, Alves, Sampaio, Goncales, 2012; Peyk, et al., 2009; Schupp, Stockburger, Bublatzky, Junghofer, Weike \& Hamm, 2007a; Schupp, Stockburger, Codispoti, Junghofer, Weike \& Hamm, 2007b). Some studies have also found effects of valence on the EPN in the form of a positivity bias (Franken, Muris, Nijs, \& van Strien, 2008; Schupp, Junghofer, Weike, Hamm, 2004b; Schupp, Stockburger, Codispoti, Junghöfer, Weike \& Hamm, 2006).

The EPN was suggested to index facilitated processing of motivationally relevant stimuli in early processing (Schupp, Stockburger, Codispoti, Junghöfer, Weike \& Hamm, 2003a, 2003b, 2004b, 2006). The generator source of the EPN was suggested to be located in occipitiotemporal-parietal regions (Schupp et al., 2007a).

EPN to emotional pictures can be seen for very short durations of picture presentation, such as only $83 \mathrm{~ms}$ (Peyk et al., 2009). Further, studies have shown that effects of emotion on EPN are independent of task-relevance (Junghöfer, Bradley, Elbert \& Lang, 2001; Schupp, Junghöfer, Wike, \& Hamm, 2003b; Schupp et al., 2003a). However, EPN amplitudes are correlated with picture composition (Nordström \& Wiens, 2012; Wiens, Sand, \& Olofsson, 2011).

\section{LPP}

The late positive potential (LPP) is shown over parietal-central electrodes when subtracting neutral pictures from emotional pictures (Luck, 2005). The resulting positivity is evident from about $300 \mathrm{~ms}$ poststimulus and usually remains throughout the entire picture presen- 
tation (Luck, 2005). Several studies also showed enhanced LPP amplitudes for some time after stimulus offset (e.g., Hajcak \& Olvet, 2008).

LPP amplitudes are positively correlated with arousal (Cuthbert, Schupp, Bradley, Birbaumer, \& Lang; Schupp, Cuthbert, Bradley, Cacioppo, Ito, \& Lang, 2000). This has been shown for both verbal ratings and electrodermal responses. Valence might also affect LPP amplitudes in the form of a negativity bias (e.g., Delplanque, Silvert, Hot \& Sequeira, 2005; Foti, Hajcak \& Dien, 2009).

Unlike many other measures of emotion, the LPP does not habituate to repeated presentations of emotional stimuli (Codispoti, Ferrari \& Bradley, 2006; 2007; Olofsson, \& Polich, 2007). Further, the LPP does not seem to be dependent on perceptual characteristics of pictures or paradigm characteristics such as stimulus duration or presentation rate (Schupp, Junghöfer, Weike, \& Hamm, 2004b; Schupp et al., 2000; De Cesarei \& Codispoti, 2006; Bradley, Hamby, Low \& Lang, 2007). One exception might be picture composition that inflates LPP amplitudes (Nordström \& Wiens, 2012; Wiens et al., 2011). Still, LPP amplitudes, especially in late parts of the interval, are primarily related to stimulus meaning. This has been shown in experiments where participants have successfully modulated LPP amplitudes by changing their appraisal of IAPS pictures (Hajcak, \& Nieuwenhuis, 2006). This effect was shown to be independent of cognitive load (Foti, \& Hajcak, 2008; MacNamara, Foti \& Hajcak, 2009). In addition, LPP amplitudes to emotional faces were shown to be dependent on conscious recognition (Wiliams et al., 2007).

Principal component analyses show that the LPP consists of multiple and overlapping positivities (Foti et al., 2009). In fact, the early LPP coincides in time with another ERP called the P3 and principal component analysis show that this first positivity in the LPP might actually be identical to the P3 (Foti et al., 2009). The hallmark of the P3 is susceptibility to cognitive factors such as stimulus probability (Luck, 2005). In contrast, the LPP is not affected by this (Cuthbert et al., 2000). Further, the longer duration of the LPP suggests some distinction from the P3. Also, unlike the P3, the LPP show a scalp topography shift from a parietal positivity in the $400-1000 \mathrm{~ms}$ range to a broader central positivity in the 1000-2000 ms range (Foti et al., 2009). 
The LPP has been suggested to index motivated attention, that is, the attentional capture by emotional stimuli (Schupp, Cuthbert, Bradley, Hillman, Hamm \& Lang, 2004a).This means that emotional stimuli are thought to be natural targets that activate the brains motivational circuits - either appetitive or aversive - in their own right. This in turn prompts an attentional set, which is indexed by the LPP. The probe P3 has been used to support this claim. The probe P3 is an ERP to the sudden onset of a sound. The P3 is dependent on available attentional resources. That is, if a concurrent task is being performed that is attentionaly demanding, the P3 amplitude will be smaller than when no task is being performed. The probe $\mathrm{P} 3$ to emotional pictures is smaller than to neutral pictures, indicating that attentional resources are consumed by the pictures (Schupp, 1997). LPP amplitudes also correlate positively with subsequent recall of pictures, as would be expected if LPP indexed enhanced processing (Dolcos \& Cabeza, 2002).

Studies found LPP amplitudes correlating positively with the BOLDsignal from visual areas, indicating facilitated or enhanced processing and thus supporting the idea that the LPP corresponds to attention (Keil, Bradley, Hauk, Rockstroh, Elbert and Lang, 2002; Sabatinelli, Lang, Keil and Bradley, 2007; Sabatinelli, Keil, Frank and Lang, 2012). Scharmüller, Leutgeb, Schäfer, Köchel and Schienle (2011) used source localization on ERP data (sLORETA) in spider phobic participants and found neural sources of LPP amplitudes (550-770 ms) in regions involved with visual processing (paracentral aeas) but also in top-down (frontal cortex) and emotional processing (cingulate cortex, insula and parahippocampal gyrus). They further located neural sources of P3 amplitudes in spider phobics to areas involved with visual processing (parieto-occipital areas). Sabatinelli et al., (2012) also found positive correlations between LPP amplitudes and the BOLDsignal from subcortical structures (amygdala, ventral striatum/nucleus accumbens, anterior insula and anterior cingulated). 


\section{Summary of studies}

\section{Study I: Spiders leave no one untouched: Spider pictures increase emotional ERPs beyond arousal and valence}

\section{Aim and background}

People with spider phobia show enhanced amplitudes of the early posterior negativity (EPN) (e. g., Junghöfer, Bradley, Elbert, \& Lang, 2001) and late positive potential (LPP) (Kolassa, Musial, Kolassa \& Miltner, 2006) to spider pictures. This indicates enhanced attention to the pictures. Both the LPP and EPN show robust correlations with arousal (Cuthbert et al., 2000; Olofsson, et al., 2008). Arousal thus seems to be important in determining the allocation of attentional resources to spider pictures in phobic participants.

The evolutionary threat hypothesis (Schimmack, 2005) might also explain the effects of emotional stimuli on attention. This hypothesis suggests that people have developed facilitated detection of stimuli that posed as threats during the evolutionary history of humans. Poisonous spiders might be an example of such threatening stimuli. If this is indeed the case, it would follow that spiders attract attention to a greater extent in humans than non-threatening stimuli that are equally high in arousal and valence.

Some studies on people with spider phobia reported comparisons between ERPs to spider and negative pictures, but the interpretations of these findings were ambiguous because spider and negative pictures were not matched on arousal and valence (e. g., Michalowski, Melzig, Weike, Stockburger, Schupp \& Hamm, 2009).

The aim of study 2 was to investigate whether there is an arousal and valence independent effect of spider pictures in phobic participants on the allocation of attention, as indexed by ERPs (P1, EPN, and LPP). 


\section{Method}

Spider pictures, negative pictures and neutral pictures were shown to 12 phobic and 15 nonphobic participants. In phobic participants, spider pictures showed larger arousal ratings than negative pictures, $t(11)$ $=2.42, p=.034, \eta_{p}^{2}=.35$, but similar valence ratings as negative pictures, $t(11)=2.0, p=.07, \eta_{p}^{2}=.27$. In nonphobic participants, spider and neutral pictures showed similar arousal, $t(14)<1, p=.57, \eta_{p}^{2}=$ .02 , and valence ratings, $t(14)<1, p=.50, \eta_{p}^{2}=.03$.

The P1 was apparent between 80 and $150 \mathrm{~ms}$ at 18 occipital electrodes (in 10/20 notation: P5 - P6, P7 - P8, PO1 - PO2, O1 - O2). The EPN was apparent between 180 and $280 \mathrm{~ms}$ at 16 electrodes (in 10/20 notation: P7-P8, PO7-PO8, O1-O2, O9-O10, PO9-PO10). The LPP was apparent between 300 and $900 \mathrm{~ms}$ at 11 electrodes (in 10/20 notation: $\mathrm{Cz}, \mathrm{CP} 1-\mathrm{CP} 2, \mathrm{P} 1-\mathrm{P} 2, \mathrm{CPz}, \mathrm{Pz}$ ). This interval was divided into three parts (300-500, 500-700, and 700-900 ms) (cf., Kolassa et al., 2006),

\section{Results}

There was a main effect of picture type on the EPN, $F(2,50)=45.82$, $p<.001, \eta^{2}=.65$, and an interaction between picture type and group, $F(2,50)=4.45, p=.02, \eta_{p}^{2}=.15$. Pairwise comparisons within each group showed that for participants with phobia, amplitudes were lower (i.e., relatively negative) for spider than negative pictures, $t(11)=$ $2.33, p=.04, \eta_{p}^{2}=.33$. For nonphobic participants, amplitudes were lower for spider than neutral pictures, $t(14)=5.05, p=.001, \eta_{p}^{2}=.65$. Paired-samples t-tests revealed that the magnitude of the difference between spider and negative pictures in participants with phobia was not larger than the magnitude of the difference between spider and neutral pictures in nonphobic participants $t(25)=1.88, p=.07, \eta_{p}^{2}=$ .12 .

For the LPP, there was an interaction between picture type and interval, $F(4,100)=20.08, p<.001, \eta^{2}=.45$. Pairwise comparisons within each group showed that for participants with phobia, amplitudes were larger for spider than negative pictures in the first interval, $t(11)$ $=3.25, p=.008, \eta_{p}^{2}=.49$. For participants without phobia, amplitudes were larger to spider than neutral pictures in the first interval, $t(14)=$ $3.38, p=.004, \eta_{p}^{2}=.45$. Paired-samples t-tests revealed that the magnitude of the difference between amplitudes to spider and negative pictures in phobic participants was similar to the magnitude of the 
difference between spider and neutral pictures in nonphobic participants, $t(25)<1, p=.66, \eta_{p}^{2}=.01$.

\section{Discussion}

The results suggest that there are two effects of spider pictures on attention as indexed by the EPN and early LPP. One effect works through arousal and valence. In this way, spider pictures capture the attention of people with phobia because the pictures are perceived as highly negative and arousing. The other effect is present in both people with and without phobia and cannot be an effect of valence and arousal because people without phobia rate spider pictures as neutral in valence and low in arousal. This effect is suggested to be the result of spiders being an evolutionary threat to humans (Schimmack, 2005). Because the effect was also present in nonphobic participants it is unlikely to play a role in the etiology of phobia.

\section{Study II: Never mind the spider: Late positive potentials to phobic threat at fixation are unaffected by perceptual load}

\section{Aim and background}

The role of attentional resources on processing of task-irrelevant stimuli has been investigated by Lavie and colleagues in a number of studies, resulting in a proposal called Load theory (Lavie, 1995). This theory states that attentional capacity is limited and is affected by the number of perceptual processes and the number of items that need to be processed, that is, the level of perceptual load. Under low perceptual load, processing of task-relevant information does not consume all attentional capacity. As a consequence, there is residual attentional capacity to process task-irrelevant information. In contrast, under high perceptual load, processing of task relevant information may consume all attentional capacity, thus leaving little or no residual attentional capacity to process task-irrelevant information.

There is extensive evidence supporting the Load theory in that perceptual load attenuates processing of task-irrelevant information when shown both at fixation and in the periphery (Lavie, 1995). Load theory predicts that, if perceptual load is sufficiently high, all processing of task-irrelevant information will seize. In support, research on processing of emotional faces suggests that task-irrelevant emotional faces are not processed under high perceptual load (Pessoa, 2005). However, because emotional faces produce only weak emotional reactions 
(Whalen, 1998), it is unresolved whether responses can be eliminated to strong emotional stimuli as easily as responses to emotional faces. Research indicates that spider pictures produce strong emotional reactions in spider-fearful individuals.

The aim of study 1 was to investigate whether processing of strong emotional but task-irrelevant pictures at fixation, as indexed by the LPP, is affected by perceptual load.

\section{Methods}

Pictures of spiders and mushrooms were shown to 15 phobic and 15 nonphobic participants. Participants performed a speeded letter discrimination task on either three (low perceptual load) or six (high perceptual load) letters that was presented surrounding the pictures. LPP was computed as the mean amplitude extracted between 300-550 ms across CP1/2, P1/2, CPz, and Pz electrodes.

\section{Results}

There was a main effect of load on $d^{\prime}$ 'in that participants performed worse during high load $\left(d^{\prime}=1.97\right.$ or $64 \%$ hits $)$ than low load $\left(d^{\prime}=\right.$ 3.31 or $85 \%$ hits), $F(1,28)=191.78, p=.001, \eta_{p}^{2}=.87$. This provides a manipulation check of load.

Spider fear interacted with picture on LPP amplitudes, $F(1,28)=$ $6.18, p=.019, \eta_{p}^{2}=.18$. Thus, the fearful group showed relatively larger LPP amplitudes to spiders $(5.60 \mu \mathrm{V})$ than mushrooms $(3.27$ $\mu \mathrm{V}), t(14)=5.16, p=.001$, compared to the nonfearful group (4.95 $\mu \mathrm{V}$ for spiders and $4.01 \mu \mathrm{V}$ for mushrooms), $t(14)=2.87, p=.012$. This provides a manipulation check of emotion. Critically, the threeway interaction with spider fear (yes and no), load (high and low), and picture type (spider, mushroom) was not significant and showed an effect size that was nil, $F<1, p>.95, \eta_{p}^{2}<.001$. This indicates that the emotional reactions to spider pictures were not moderated by perceptual load.

\section{Discussion}

Because task-irrelevant spiders at fixation elicited enhanced LPP amplitudes in spider-fearful individuals even under high perceptual load, the present findings provide evidence for the processing of taskirrelevant but potent emotional pictures independently of attention. These results provide a limit of Load theory in that perceptual load 
may have little if any effects on processing of strong emotional pictures at fixation.

\section{Study III: Similar effects of manipulations of attention on pro- cessing of phobic and nonphobic pictures}

\section{Aim and background}

Studies have produced mixed findings on whether emotional stimuli can be processed without attention. First, ERPs to emotional pictures in attended to unattended locations were investigated. These studies showed that LPP amplitudes to both negative pictures from the International Affective Picture System (IAPS) (Lang, Bradley, \& Cuthbert, 2008) and pictures of fearful faces were eliminated when spatial attention was directed away from the pictures (e.g., De Cesarei, Codispoti, \& Schupp, 2009). However, results were less consistent for the EPN. Whereas some studies reported reductions of amplitudes when emotional pictures were presented in unattended locations (e.g., De Cesarei, Codispoti, \& Schupp, 2009), others reported null findings (e.g., Sand, \& Wiens, 2011).

Second, ERPs to emotional pictures were studied while participants performed a task that could be varied in perceptual load. For example, Sand and Wiens (2011) presented negative and neutral IAPS pictures at fixation to participants as they performed a letter discrimination task. In both studies, participants showed enhanced LPP amplitudes to negative IAPS pictures when compared to neutral IAPS pictures. However, these LPP amplitudes did not differ between low and high load, indicating that emotional processing was independent of perceptual load. In contrast, Schupp, Stockburger, Bublatzky, Junghöfer, Weike and Hamm (2007) asked participants to perform a line counting task that was superimposed on IAPS pictures presented rapidly $(3 \mathrm{~Hz})$ in a continuous stream. Results showed an EPN to negative pictures that was reduced when the line counting task was made more difficult.

It is possible that phobic and nonphobic stimuli are affected differently by spatial attention and perceptual load. Norberg, Peira and Wiens (2010) showed pictures of spiders and mushrooms at fixation to participants with and without spider phobia. Participants simultaneously performed a letter discrimination task in the periphery of the pictures on either three (low load) or six (high load) letters. The results showed that enhanced amplitudes of the LPP to spider pictures in phobic par- 
ticipants did not differ between low and high load. Thus, the result suggested that phobic processing, just as nonphobic emotional processing, is independent of perceptual load.

However, effects of spatial attention and perceptual load have never been compared between phobic and nonphobic emotional stimuli in a single experiment in which picture types were matched in relevant characteristics. For this reason, the aim of study 3 was to compare phobic and nonphobic processing during manipulations of spatial attention and increased perceptual load. Processing of emotional stimuli was indexed by ERPs at several latencies.

\section{Methods}

Spider pictures, negative pictures and neutral pictures were shown to 13 phobic and 15 nonphobic participants. In phobic participants, spider and negative pictures showed similar arousal, $t(12)=2.12, p=.06$, $\eta_{p}^{2}=.27$, and valence ratings, $t(12)=1.70, p=.11, \eta_{p}^{2}=.20$. In nonphobic participants, spider and neutral pictures showed similar arousal, $t(14)<1, p=.57, \eta_{p}^{2}=.02$, and valence ratings, $t(14)<1, p=.50$, $\eta_{p}^{2}=.03$.

The P1 was apparent between 80 and $150 \mathrm{~ms}$ at 18 occipital electrodes (in 10/20 notation: P5 - P6, P7 - P8, PO1 - PO2, O1 - O2). The EPN was apparent between 180 and $280 \mathrm{~ms}$ at 16 electrodes (in 10/20 notation: P7-P8, PO7-PO8, O1-O2, O9-O10, PO9-PO10). The LPP was apparent between 300 and $900 \mathrm{~ms}$ at 11 electrodes (in 10/20 notation: $\mathrm{Cz}, \mathrm{CP} 1-\mathrm{CP} 2, \mathrm{P} 1-\mathrm{P} 2, \mathrm{CPz}, \mathrm{Pz})$. This interval was divided into two parts (300-500 and 500-700) (cf., Kolassa et al., 2006),

\section{Results}

\section{Spatial attention}

For the EPN, there was no three-way interaction between task, picture type, and group, $p=.68, \eta_{p}{ }^{2}=.014$, and no two-way interaction between task and picture type, $p=.89, \eta_{p}{ }^{2}=.004$. This indicates no effect of spatial attention on EPN

For the LPP, there was no three-way interaction between picture type, task and group, $p=.63 . \eta_{p}^{2}=.017$. However, there was a two-way interaction between task and picture type, $F(2,52)=3.97, p=.028$, $\eta_{p}^{2}=.13$. Amplitude differences between negative and neutral pictures 
decreased when going from no load $(m=1.74 \mu \mathrm{V})$ to low load $(m=$ $0.97 \mu \mathrm{V}), F(1,26)=6.38, p=.018, \eta_{p}^{2}=.20$. This indicates an effect of spatial attention on the LPP to negative pictures. Analyses of only the phobic group showed that the difference between spider and negative pictures was not moderated by load, $p=.73, \eta^{2}=.01$. This indicates that spatial attention had similar effects to negative and spider pictures in phobic participants.

\section{Perceptual load}

For the EPN, there was no three-way interaction between task, picture type, and group, $p=.92, \eta_{p}^{2}=.006$, and no two-way interaction between task and picture type, $p=.17, \eta_{p}^{2}=.062$. This indicates no effects of perceptual load on spider or negative pictures for the EPN.

For the LPP, there was no interaction between task and picture type, $p$ $=.18, \eta_{p}^{2}=.060$, and no interaction between task, picture type, and group, $p=.58, \eta_{p}^{2}=.025$. This indicates no effect of perceptual load on spider or negative pictures for the LPP.

\section{Discussion}

Results showed no differences between phobic and nonphobic pictures in effects of spatial attention or perceptual load. For the whole sample, LPP amplitudes to negative pictures decreased when their location was task-irrelevant. Notably, LPP amplitudes to spider pictures in phobics showed similar effects as negative pictures. However, for the EPN, no effects of spatial attention were found for either picture type. For perceptual load, there were no effects on emotional processing. 


\section{General discussion}

Study 1 showed enhanced LPP amplitudes to phobic pictures independent of arousal and valence. Further, this effect was present in both phobic and nonphobic participants. Study 2 showed no effect of perceptual load on LPP to phobic pictures. Study 3 showed that spatial attention reduced LPP amplitudes, but not EPN amplitudes, and to a similar extent for both phobic and nonphobic pictures. Perceptual load did not reduce EPN or LPP amplitudes to either phobic or nonphobic pictures.

Study 1 showed two effects of spider pictures on EPN and LPP. First, there was an effect of arousal and valence. Because only phobic participants were afraid of spiders, this effect was present only in them. Second, there was also an effect of spider pictures that was independent of arousal and valence. This effect was present in both phobic and nonphobic participants and might be explained by the evolutionary threat hypothesis (Schimmack, 2005). This hypothesis suggests that humans have developed an attentional bias to spiders because spiders posed a threat to humans during evolution.

To understand the difference between the effect of arousal and valence on the one hand, and the effect of evolutionary threat on the other, it is necessary to separate proximate and ultimate explanations (Tinbergen, 1963). Proximate explanations account for the existence of a phenomenon in terms of its mechanical causes. In contrast, ultimate explanations account for the existence of a phenomenon in terms of its evolutionary function, that is, how it increases chances of survival and reproduction. Importantly, these two types of explanations are not mutually exclusive. Rather, they complement each other. Whereas proximate explanations try to unveil relations of mechanistic causality, ultimate explanations try to account for the existence of these relationships as evolutionary adaptions. 
The evolutionary threat hypothesis (Schimmack, 2005) is an ultimate explanation. This means that it accounts for the arousal and valence independent association between spider pictures and attention observed in study 1 by assuming that this association has led to increased chances of survival in humans. For that reason, the association has grown more frequent in the population until it was omnipresent. However, there was also an effect of arousal and valence on attention. Arousal and valence might in this case be thought of as mediating a relationship between spider pictures and attention. Accounting for the effect of spider pictures on attention in terms of arousal and valence would be to give it a proximal explanation. The existence of this association could then in its turn be accounted for by an ultimate explanation. Why is there such a relationship between emotion and attention? Prepardness theory (Seligman, 1971) attempts to explain this relationship. That is, the reason why arousal and valence leads to enhanced attention is that it by doing so enhances chances of survival.

There are therefore two ways in which evolution could increase attention to spiders. First, it could make people more afraid of them, that is, increase arousal and valence associated with spiders. Spider phobia might be an example of this. In addition to this, evolution could also create a link between spiders and attention that is not mediated by arousal and valence. This is the arousal and valence independent effect of spider pictures on attention that was found in study 1 and there accounted for in terms of evolutionary threat.

The effect of spider pictures on ERPs that was independent of arousal and valence is likely not involved in the etiology of phobia. This is because it was present also in nonphobics. Further understanding of the etiology of phobia should therefore focus on the effect of spiders related to arousal and valence. For the same reason, treatment of phobia is likely to benefit from focusing on the effect related to arousal and valence.

Study 2 showed that processing of phobic stimuli was independent of perceptual load. This was in contrast to previous studies (Erthal, de Oliveira, Mocaiber, Pereira, Machado-Pinheiro, et al., 2005; OkonSinger et al., 2007; Pessoa, 2005). However, previous studies did typically use nonphobic stimuli. It was, therefore, possible that perceptual load moderates nonphobic emotional processing but leaves phobic processing intact. However, study 3 compared effects of perceptual 
load on phobic and nonphobic processing and found no difference. Some other explanation for the discrepant results must therefore be found. Several previous studies frequently used pictures of fearful faces as emotional stimuli. However, fearful faces constitute relatively weak emotional stimuli (Whalen, 1998). In contrast, spiders are more potent to spider phobic people (Globisch, Hamm, Esteves \& Öhman, 1999). For that reason, it is possible that perceptual load can reduce weak but not strong emotional processing.

Failure to reduce LPP amplitudes could also be a result of the perceptual load manipulation being too weak. A higher perceptual load, for example one consisting of eight instead of six letters, might have reduced LPP amplitudes. The conclusion that phobic processing is never moderated by perceptual load might therefore be much too strong. However, it seems reasonable to conclude that processing related to potent emotional stimuli are more difficult to reduce with perceptual load than for example processing of fearful faces.

Also statistical power might be an issue. Obviously, the effects of perceptual load on LPP amplitudes would have been significant if the study had had greater statistical power. This could have been achieved by increasing the number of participants. Still, any effect can be made statistically significant in this way, no matter how small it is. This means that every successful attempt to show emotional processing without attention could in principle be criticized as lacking in power. The reasonable way to resolve this in the framework of classical hypothesis testing would be to look at effect sizes and judge from them what would be a reasonable interpretation. In the case of perceptual load on LPP, effect sizes was $\eta_{p}^{2}<.001$ in study 2 and $\eta_{p}^{2}=.060$ for nonphobic pictures and $\eta_{p}^{2}=.025$ for phobic pictures in phobic participants in study 3. These effect sizes are small enough to judge in favor for the perspective that emotional processing is possible during high perceptual load.

Study 3 also extended the results from study 2 by investigating effects of spatial attention on phobic and nonphobic stimuli. Once again, there was no difference between phobic and nonphobic pictures. However, unlike perceptual load, spatial attention did reduce LPP amplitudes to emotional pictures. This was in agreement with previous studies (e.g., De Cesarei, Codispoti, \& Schupp, 2009; Holmes, Vuilleumier, \& Eimer, 2003). However, no effects were found on 
EPN for either phobic or nonphobic pictures. Indeed, previous studies on EPN have produced mixed findings (e. g., De Cesarei, Codispoti, \& Schupp, 2009; Sand \& Wiens, 2011).

To conclude, the present thesis aimed at investigating attention in phobia. For this reason, two research questions were formulated. The first one was: do emotional pictures attract attention to a greater extent than what can be expected from arousal and valence? The results suggest that phobic pictures do indeed evoke ERP amplitudes to a greater extent than nonphobic pictures. The second research question was: are effects of spatial attention and perceptual load on ERPs the same for phobic and nonphobic emotional pictures? The results suggest that ERPs to phobic and nonphobic pictures are moderated similarly by picture location and perceptual load. 


\section{References}

Adamo, M., Pun, C., Pratt, J., \& Ferber, S. (2008). Your divided attention, please! The maintenance of multiple attentional control sets over distinct regions in space. Cognition, 107, 295-303.

Barrett, L. F. (2006). Are emotions natural kinds? Perspectives on psychological science, 1, 28-58.

Barrett, L. F., \& Wager, T. D. (2006). The structure of emotion. Current directions in psychological science, 15, 79-83.

Bijl, R. V., Ravelli, A., \& van Zessen, G. (1998). The Netherlands mental health survey and incidence study (NEMESIS). Social Psychiatry and Psychiatric Epidemiology, 33, 587-595.

Bradley, M. M., Hamby, S., Low, A., \& Lang, P. J. (2007). Brain potentials in perception: Picture complexity and emotional arousal. Psychophysiology, 44, 364-373.

Bradley, M. M., Sabatinelli, D., Lang, P. J., Fitzsimmons, J. R., King, W., \& Desai, P. (2003). Activation of the visual cortex in motivated attention. Behavioral Neuroscience, 117, 369-380.

Breiter, H. C., Etcoff, N. L., Whalen, P. J., Kennedy, W. A., Rauch, S. L., Buckner, R. L., et al. (1996). Response and habituation of the human amygdala during visual processing of facial expression. Neuron, 17, 1-13.

Broadbent, D. E. (1958). Perception and Communication. London: Pergamon Press.

Cherry, E. C. (1953). Some experiments on the recognition of speech, with one and with two ears. Journal of the Acoustic Society of America, 25, 975-979. 
Clark, V. P., Fan, S., \& Hillyard, S. A. (1995). Identification of early visual evoked potential generators by retinotopic and topographic analyses. Human Brain Mapping, 2, 170-187.

Clark, V. P., \& Hillyard, S. A. (1996). Spatial selective attention affects early extrastriate but not striate components of the visual evoked potential. Journal of Cognitive Neuroscience, 8, 387-402.

Codispoti, M., Ferrari, V., \& Bradley, M. M. (2006). Repetitive picture processing: Autonomic and cortical correlates. Brain Research, 1068, 213-220.

Codispoti, M., Ferrari, V., \& Bradley, M. M. (2007). Repetition and event-related potentials: Distinguishing early and late processes in affective picture perception. Journal of Cognitive Neuroscience, 19, 577-586.

Cooper, R. M., \& Langton, S. R. H. (2006). Attentional bias to angry faces using the dot-probe task. It depends when you look for it. Behavior Research and Therapy, 44, 1321-1329.

Cuthbert, B. N., Schupp, H. T., Bradley, M. M., Birbaumer, N., \& Lang, P. J. (2000). Brain potentials in affective picture processing: covariation with automatic arousal and affective report. Biological Psychology, 52, 95-111.

Darwin, C. (1872). The expression of the emotions in man and animals. London: John Murray.

De Cesarei, A., \& Codispoti, M. (2006). When does size not matter? Effects of stimulus size on affective modulation. Psychophysiology, 43, 207-215.

De Cesarei, A., Codispoti, M., \& Schupp, H. T. (2009). Peripheral vision and preferential emotion processing. Neuroreport, 20, 14391443.

Delplanque, S., Silvert, L., \& Hot, P. (2005). Event-related P3a and $\mathrm{P} 3 \mathrm{~b}$ in response to unpredictable emotional stimuli. Biological Psychology, 68, 107-120. 
Deutsch, J. A., \& Deutsch, A. (1963). Attention - some theoretical considerations. Psychological Review, 70, 80-90.

Di Russo, F., Martinez, A., \& Hillyard, S. A. (2003). Source analysis of event-related cortical activity during visuo-spatial attention. Cerebral Cortex, 13, 486-499.

Di Russo, F., Martinez, A., Sereno, M. I., Pitzalis, S., \& Hillyard, S. A. (2002). Cortical sources of the early components of the visual evoked potential. Human Brain Mapping, 15, 95-111.

Dolcos, F., \& Cabeza, R. (2002). Event-related potentials of emotional memory: Encoding pleasant, unpleasant, and neutral pictures. Cognitive, Affective, and Behavioral Neuroscience, 2, 252-263.

Driver, J., \& Baylis, G. C. (1989). Movement and visual attention: The spotlight metaphor breaks down. Journal of Experimental Psychology: Human Perception and Performance, 15, 448-456.

Ekman, P. (1992). Are there basic emotions? Psychological review, 99, 550-553.

Eriksen, C. W., \& st James, J. O. (1986). Visual attention within and around the field of focal attention: a zoom lens model. Perception and psychophysics, 40, 225-240.

Erthal, F. S., de Oliveira, L., Mocaiber, I., Pereira, M. G., MachadoPinheiro, W., Volchan, E., et al. (2005). Load-dependent modulation of affective picture processing. Cognitive Affective \& Behavioral Neuroscience, 5, 388-395.

Etkin, A. \& Wager, T. D. (2007). Functional neuroimaging of anxiety: a meta-analysis of emotional processing in PTSD, social anxiety disorder, and specific phobia. American Journal of Psychiatry, 164, 1476-1488.

Field, A. P. (2006). Is conditioning a useful framework for understanding the development and treatment of phobias? Clinical Psychological Review, 26, 857-875. 
Foti, D., \& Hajcak, G. (2008). Deconstructing reappraisal: Descriptions preceding arousing pictures modulate the subsequent neural response. Journal of Cognitive Neuroscience, 20, 977-988.

Foti, D., Hajcak, G., \& Dien, J. (2009). Differentiating neural responses to emotional pictures: evidence from temporal-spatial PCA. Psychophysiology, 46, 521-530.

Franken, I., Muris, P., Nijs, I., \& van Strien, J. (2008). Processing of pleasant information can be as fast and strong as unpleasant information: Implications for the negativity bias. Netherlands Journal of Psychology, 64, 168-176.

Fredrikson, M., Annas, P., Fischer, H., \& Wik, G. (1996). Gender and age differences in the prevalence of specific fears and phobias. Behavior research and therapy, 34, 33-39.

Fredrikson, M., Wik, G., Annas, P., Ericson, K. A. J., \& StoneElander, S. (1995). Functional neuroanatomy of visually elicited simple phobic fear: Additional data and theoretical analysis. Psychophysiology, 32, 43-48.

Fredrikson, M., Wik, G., Greitz, T., Eriksson, L., Stone-Elander, S., Ericson, K. A. J., et al. (1993). Regional cerebral blood flow during experimental phobic fear. Psychophysiology, 30, 126-130

Globisch, J., Hamm, A. O., Esteves, F., \& Öhman, A. (1999). Fear appears fast: Temporal course of startle reflex potentiation in animal fearful subjects. Psychophysiology, 36, 66-75.

Hajcak, G., \& Nieuwenhuis, S. (2006). Reappraisal modulates the electrocortical response to unpleasant pictures. Cognitive, Affective, \& Behavioral Neuroscience, 6, 291-297.

Hajcak, G., \& Olvet, D. M. (2008). The persistence of attention to emotion: Brain potentials during and after picture presentation. Emotion, 8, 250-255.

Holmes, A., Vuilleumier, P., \& Eimer, M. (2003). The processing of emotional facial expression is gated by spatial attention: evidence 
from event-related brain potentials. Cognitive Brain Research, 16,174184.

Jans, B., Peters, J. C., \& de Weerd, P. (2010). Visual spatial attention to multiple locations at once: the jury is still out. Psychological review, 117, 637-684.

Jensen, A. R., \& Rohwer, W. D. (1966). Stroop color word test - a review. Acta Psychologica, 25, 36-93.

Jiang, Y. H., \& Chun, M. M. (2001). Selective attention modulates implicit learning. Quarterly Journal of Experimental Psychology. 54, 1105-1124.

Junghöfer, M., Bradley, M. M., Elbert, T. R., \& Lang, P. J. (2001). Fleeting images: a new look at early emotion discrimination. Psychophysiology, 38, 175-178.

Junghöfer, M., Sabatinelli, D., Bradley, M. M., Schupp, H. T., Elbert, T. R., Lang, P. J. (2006). Fleeting images: rapid affect discrimination in the visual cortex. NeuroReport, 1, 225-229.

Keil, A., Bradley, M. M., Hauk, O., Rockstroh, B., Elbert, T. \& Lang, P. J. (2002). Large-scale neural correlates of affective picture processing. Psychophysiology, 39, 641-649.

Kessler, R. C., Berglund, P., Demler, O., Jin, R., Merikangas, K. R., \& Walters, E. E. (2005). Lifetime prevalence and age-of-onset distributions of DSM-IV disorders in the national comorbidity survey replication. Archives of general psychiatry, 62, 593-602.

Khaneman, D. (1973). Attention and effort. Englewood Cliffs, NJ: Prentice Hall.

Kolassa, I.-T., Musial, F., Kolassa, S., \& Miltner W. H. R. (2006). Event-related potentials when identifying or color-naming threatening schematic stimuli in spider phobic and non-phobic individuals. $B M C$ Psychiatry, 6, 38.

Konorski, J. (1967). Integrative activity of the brain: an interdisciplinary approach. Chicago: University of Chicago Press. 
LaBar, K. S., Gitelman, D. R., Parrish, T. B., Kim, Y. H., Nobre, A. C., \& Mesulam, M. M. (2001). Hunger selectively modulates corticolimbic activation to food stimuli in humans. Behavioral Neuroscience, $115,493-500$.

LaBerge, D. (1983). Spatial extent of attention to letters and words. Journal of experimental psychology, 9, 371-379.

Lang, P. J., Bradley, M. M., \& Cuthbert, B. N. (2008). International Affective Picture System (IAPS): affective ratings of pictures and instruction manual. Technical Report A-8. University of Florida, Gainesville, FL.

Lang, P. J., \& Davis, M. (2006). Emotion, motivation, and the brain: reflex foundations in animal and human research. Progress in brain research, 156, 3-29.

Lang, P. J., Davis, M., Öhman, A. (2000). Fear and anxiety: animal models and human cognitive psychophysiology. Journal of Affective Disorders, 61, 137-159.

Lavie, N. (1995). Perceptual load as a necessary condition for selective attention. Journal of Experimental Psychology: Human perception and Performance, 21, 451-468.

Lavie, N. (2010). Attention, distraction, and cognitive control under load. Current Directions in Psychological Science, 19, 143-148.

Lavie, N., \& Fox, E. (2000). The role of perceptual load in negative priming. Journal of Experimental Psychology, Human perception and performance, 26, 1038-1052.

Lavie, N., Hist, A., de Fockert, J. W., \& Viding, E. (2004). Load theory of selective attention and cognitive control. Journal of Experimental Psychology: General, 133, 339-354.

Lavie, N., Ro, T., \& Russell, C. (2003). The role of perceptual load in processing of distractor faces. Psychological Science, 14, 510-515.

Ledoux, J. (1998). The emotional brain. NY: Weidenfeld \& Nicolson. 
Leite, J., Carvalho, S., Galdo-Alvarez, S., Alves, J., Sampaio, A., \& Goncales, Ó. F. (2012). Affective picture modulation: Valence, arousal, attention allocation and motivational significance. International Journal of Psychophysiology, 83, 375-381.

Luck, S. (2005). An introduction to the event-related potential technique. Cambridge: The MIT Press.

MacNamara, A., Foti, D., \& Hajcak, G. (2009). Tell me about it: Neuronal activity elicited by emotional stimuli and preceding descriptions. Emotion, 9, 531-543.

Michalowski, J. N., Melzig, C. A., Weike, A. I., Stockburger, J., Schupp, H. T., \& Hamm, A. O. (2009). Brain dynamics in spiderphobic individuals exposed to phobia-relevant and other emotional stimuli. Emotion, 9, 306-315.

Miyake, A., Friedman, N. P., Emerson, M. J., Witzki, A. H., \& Howerter, A. (2000). The unity and diversity of executive functions and their contributions to complex "frontal lobe" tasks: a latent variable analysis. Cognitive Psychology, 41, 49-100.

Miyake, A., \& Friedman, N. P. (2012). The nature and organization of individual differences in executive functions: four general conclusions. Current Directions in Psychological Science, 21, 8-14.

Moffitt, T. E., Caspi, A., Taylor, A., Kokaua, J., Milne, B. J., Polanczyk, G., et al. (2010). How common are common mental disorders? Psychological Medicine, 40, 899-909.

Moray, N. (1959). Attention in dichtotic listening: affective cues and the influence of instructions. Quartely Journal of Experimental Psychology, 11, 56-60.

Muller, M. M., \& Hubner, R. (2002). Can the spotlight of attention be shaped like a dougnut? Evidence from steady-state visual evoked potentials. Psychological Science, 13, 119-124.

Muller, H. J., \& Rabbitt, P. M. (1989). Reflexive orienting of visual attention: time course of activation and resistance to interruption. 
Journal of Experimental Psychology: Human Perception and Performance, 15, 315-330.

Norberg, J., Peira, N., \& Wiens, S. (2010). Never mind the spider: Late positive potential to phobic threat at fixation are unaffected by perceptual load. Psychophysiology, 47, 1151-1158.

Nordström, H., \& Wiens, S. (2012). Emotional event-related potentials are larger to figures than scenes but are similarly reduced by inattention. BMC Neuroscience, 13, 49.

O’Connor, D. H., Fukui, M. M., Pinsk, M. A., \& Kastner, S. (2002). Attention modulates responses in the human lateral geniculate nucleus. Nature neuroscience, 5, 1203-1209.

Okon-Singer, H., Tzelgov, J., \& Henik, A. (2007). Distinguishing between automaticity and attention in the processing of emotionally significant stimuli. Emotion, 7, 147-157.

Olofsson, J. K., Nordin, S., Sequeira, H., \& Polish, J. (2008). Affective picture processing: An integrative review of ERP findings. Biological Psychology, 77, 247-265.

Olofsson, J. K., \& Polich, J. (2007). Affective visual event-related potentials: Arousal, repetition, and time-on-task. Biological Psychology, 75, 101-108.

Paelecke, M., Paelecke-Habermann, Y., \& Borkenau, P. (2012). Temperament and attentional bias in vocal emotional stroop tasks. European Journal of Personality, 26, 111-122.

Pessoa, L., \& Adolphs, R. (2010). Emotion processing and the amygdala: from a "low road" to "many roads" of evaluating biological significance. Nature, 11, 773-782.

Pessoa, L., Padmala, S., \& Morland, T. (2005). Fate of unattended fearful faces in the amygdala is determined by both attentional resources and cognitive modulation. NeuroImage, 28, 249-255. 
Peyk, P., Schupp, H. T., Keil, A., Elbert, T., \& Junghofer, M., (2009). Parallel processing of affective visual stimuli. Psychophysiology, 46, 200-208.

Pinsk, M. A., Doniger, G. M., \& Kastner, S. (2004). Push-pull mechanism of selective attention in human extrastriate cortex. Journal of Neurophysiology, 92, 622-629.

Pourtois, G., Grandjean, D., Sander, D., \& Vuilleumier, P. (2004). Electrophysiological correlates of rapid spatial orienting towards fearful faces. Cerebral Cortex, 14, 619-633.

Rees, G., Frith, C. D., \& Lavie, N. (1997). Modulating irrelevant motion perception by varying attentional load in an unrelated task. Science, 279, 1616-1619.

Reiman, E. M., Lane, R. D., Ahern, G. L., Schwartz, G. E., Davidson, R. L., Friston, K. J., et al. (1997). Neuroanatomical correlates of externally and internally generated human emotion. American Journal of Psychiatry, 154, 918-925.

Sabatinelli, D., Bradley, M. M., Fitzsimmons, J. R., Lang P. J. (2005). Parallel amygdala and inferotemporal activation reflect emotional intensity and fear relevance. NeuroImage, 4,1265-1270.

Sabatinelli, D., Keil, A., Frank, D. W., \& Lang (2012). Emotional perception: correspondence of early and late event-related potentials with cortical and subcortical function MRI. Biological Psychology, in press.

Sabatinelli, D., Lang, P. J., Keil, A., Bradley, M. M. (2007). Emotional perception: correlation of functional MRI and event-related potentials. Cerebral Cortex, 17, 1085-1091.

Sand, A., \& Wiens, S. (2011). Processing of unattended, simple negative pictures resists perceptual load. Neuroreport, 22, 348-352

Scharmüller, W., Leutgeb, V., Schäfer, A., Köchel, A., \& Schienle, A. (2011). Source localization of late electrocortical positivity during symptom provocation in spider phobia: an sloreta study. Brain Research, 10-18. 
Schimmack, U. (2005). Attentional interference effects of emotional pictures: Threat, negativity or arousal? Emotion, 5, 55-66.

Schupp, H. T., Cuthbert, B. N., Bradley, M. M., Birbaumer, N., \& Lang, P. J. (1997). Probe P3 and blinks: two measures of affective startle modulation. Psychophysiology, 34, 1-6.

Schupp, H. T., Cuthbert, B. N., Bradley, M. M., Cacioppo, J. T., Ito, Tiffany, \& Lang, P. J. (2000). Affective picture processing: the late positive potential is modulated by motivational relevance. Psychophysiology, 37, 257-261.

Schupp, H. T., Cuthbert, B. N., Bradley, M. M., Hillman, C. H., Hamm, A. O., \& Lang, P. J. (2004a). Brain processes in emotional perception: motivated attention. Cognition and Emotion, 18, 593-611.

Schupp, H. T., Junghofer, M., Weike, A. I., \& Hamm, A. O. (2003a). Attention and emotion: an ERP analysis of facilitated emotional stimulus processing. Neuroreport, 14, 1107-1110.

Schupp, H. T., Junghofer, M., Weike, A. I., \& Hamm, A. O. (2003b). Emotional facilitation of sensory processing in the visual cortex. Psychological Science, 14, 7-13.

Schupp, H. T., Junghofer, M., Weike, A. I., Hamm, A. O. (2004b). The selective processing of briefly presented affective pictures: an ERP analysis. Psychophysiology, 41, 441-449.

Schupp, H. T., Stockburger, J., Bublatzky, F., Junghofer, M., Weike, A. I., \& Hamm, A. O. (2007a). Explicit attention interferes with selective emotion processing in human extrastriate cortex. $B M C$ Neuroscience, 8, 16.

Schupp, H. T., Stockburger, J., Codispoti, M., Junghöfer, M., Weike, A. I., \& Hamm, A. O. (2006). Stimulus novelty and emotion perception: The near absence of habituation in the visual cortex. NeuroReport, 17, 365-369. 
Schupp, H. T., Stockburger, J., Codispoti, M., Junghofer, M., Weike, A.I., \& Hamm, A. O., (2007b). Selective visual attention to emotion. Journal of Neuroscience, 27, 1082-1089.

Schwartz, S., Vuilleumier, P., Hutton, C., Maravita, A., Dolan, R. J., \& Driver, J. (2005). Attentional load and sensory competition in human vision: Modulation of fMRI responses by load at fixation during task-irrelevant stimulation in the peripheral visual field. Cerebral Cortex, 15, 770-786.

Seligman, M. E. P. (1971). Phobias and preparedness. Behavior Therapy, 2, 307-320.

Stormark, K. M., Nordby, H., \& Hugdahl, K. (1995). Attentional shifts to emotionally charged cues - behavioral and ERP data. Cogntion \& Emotion, 9, 507-523.

Styles, E. A. (2006). The Psychology of Attention. NY: Psychology Press.

Tinbergen, N. (1963). On the aims and methods of ethology. Zeitschrift für Tierpsychologie, 20, 410-433.

Treisman, A. (1982). Perceptual grouping and attention in visual search for features and for objects. Journal of Experimental Psychology, $8,194-214$.

Vogel, E. K., \& Luck, S. J. (2000). The visual N1 component as an index of a discrimination process. Psychophysiology, 37, 190-203.

Vuilleumier, P., Armony, J. L., Driver, J., \& Dolan, R. J. (2001). Effects of attention and emotion on face processing in the human brain: An event-related fMRI study. Neuron, 30, 829-841.

Vuilleumier, P. (2005). How brains beware: Neural mechanisms of emotional attention. Trends in Cognitive Sciences, 9, 585-594.

Weinberg, A., \& Hajcak, G. (2010). Beyond good and evil: the timecourse of neural activity elicited by specific picture content. Emotion, $10,767-782$. 
Whalen, P. J. (1998). Fear, vigilance, and ambiguity: Initial neuroimaging studies of the human amygdala. Current Directions in Psychological Science, 7, 177-188.

Wiliams, L. M., Kemp, A. H., Felmingham, K., Liddell, B. J., Palmer, D. M., \& Bryant, R. A. (2007). Neural biases to covert and overt signals of fear: Dissociation by trait anxiety and depression. Journal of Cognitive Neuroscience, 19, 1595-1608.

Wiens, S., Sand, A., \& Olofsson, J. (2011). Nonemotional features suppress early and enhance late emotional electrocortical reponses to negative pictures. Biological Psychology, 86, 83-89. 